\title{
SHORT SUPPLY CHAIN OF WASTE FLOWS: DESIGNING LOCAL NETWORKS FOR LANDSCAPE REGENERATION
}

\section{Marina Rigillo *, Enrico Formato and Michelangelo Russo}

Department of Architecture, University of Naples Federico II (UNINA), via Forno Vecchio 36, 80134 Napoli, Italy

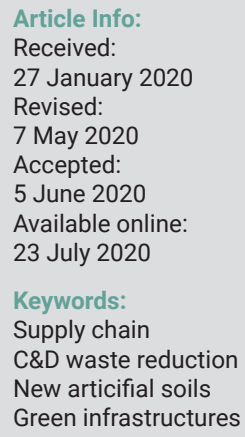

\begin{abstract}
Creating a circular economy poses multiple challenges yet has social opportunity. It represents a key approach to implement the management of more sustainable waste flows to achieve win-win solutions consistent with the EU environment goals, and with the social-economic expectations. As part of the comprehensive outcomes of the EU funded research project REPAIR, the paper presents the results for new technological soils, designed with the aim of implementing the number of products coming from the recycling of both C\&D waste and organic waste. The paper discusses the technical issues of this solution in the framework of the specific characteristic of its supply chain. The research aim is focused on the design approach, working on the new products and process at once. Further, the project highlights the importance of dedicated local networks for sharing knowledge in between different stakeholders and experts, and for promoting innovation at local scales.
\end{abstract}

\section{INTRODUCTION}

The paper presents several of the outcomes of the EU Horizon 2020 program - REPAiR (REsource Management in Peri-urban Areas). The project aligns with several initiatives of the European Commission oriented toward establishing circular economy processes by limiting resource consumption and waste disposal (EC, 2010; EC Horizon 2020, 2019; EEA European Environment Agency, 2015). The general aim of the project is reducing waste flows through a better use of secondary raw materials, especially focusing on Construction and Demolition Waste (CDW) and Organic Waste (OW). These categories are both included in the priority list identified by the EU Action Plan for Circular Economy (COM (2015) 614 final) due to their value-chains potentials and their environmental footprint. Further, C\&D waste is the largest flow in the EU based on volume (EU Commission, 2018), while organic waste (namely bio-waste), is estimated at $180 \mathrm{~kg} /$ pro capita/ per year (EU Parliament, 2015).

According to these insights, the specific aim of the research is to figure out new forms of circularity, addressing recycle and reuse of both C\&D waste and bio-waste through the design of innovative processes, specially focusing on the opportunities of implementing collaborative design practices. The paper presents the results of the DiARC research team, stressing the concern of short supply-chain and local networks as key strategies for promoting recycle and reuse at local scales. Despite the fact that the recycling operations for C\&D waste and bio-waste are not complex (due to they both work on well established technologies), the management of their supply-chain is quite hard because it includes the collaborations of manifold subjects; the compliance of strict regulatory standards, and it provides low economic returns. Additionally, the major challenge in reducing waste flows is the systemic approach to the design process, embedding economic issues, social habits and technological responses into planning (EU, 2013).

This research also assumes that the transition toward more sustainable waste management is not only a technical matter but it depends on creative visions by which breaking the circuit "take-make-dispose", and promoting design solutions for implementing circularity locally, stressing the concept of a OKM supply-chain. Research background concerns two main fileds of interests: 1) planning approach, by which it is possible to integrate the goals of waste reduction into the comprehensive territorial strategy, especially focuses on the regeneration of peri-urban areas; and 2) the design of artificial soils, as Eco-Innovative Solutions (EIS) aimed at both producing ecosystem services and new public spaces (Rigillo et al., 2018). These solutions will potentially lead to the modification of existing waste flows, reducing the impacts coming from transport (mainly economic), and implementing the recycling of raw materials into new flows and processes. Moreover, the artificial soils are designed for being part of new green-infrastructures in the peri-urban area, producing original landmarks for these areas often under-used, abandoned and/ or polluted. 
As part of the research assumption, the paper posits short supply chain as prime condition to re-think waste management as site specific and eco-innovative process, facilitating circular economies locally, and offering benefits for local inhabitants and stakeholders. Short supply chain can reduce current costs and the impacts related to waste transport; it improves the awareness of local communities about the potential value of wastes, and strengthens the importance of user's habits in separating household waste (Berruti, Palestino 2017). The research devises a set of "overlapping networks" (Figure 1) as collaborative strategy for developing co-design experience, merging different competences and expertise into dedicated Living Labs. The networks focus on the goal of shortening waste supply chain locally through the proposal of a new recycled product (techno-soil) made by the combining of construction debris and compost. Further the different Labs validated the latter in operational and regulatory terms, and spent their expertise for designing the new peri-urban landscapes (namely green infrastructure and new public spaces). Techno-soils have been here interpreted as innovative resources thanks to the implementation of more inclusive design approach, decoupling economic growth from resource consumption and environmental depletion (UNEP, 2011).

\section{STEPS IN METHODS}

\subsection{Case study area}

REPAiR focuses on peri-urban areas, intended as territories characterised by a mix of dispersed urbanised and rural areas, interlinked with infrastructures, agriculture and natural patches (Formato, Amenta \& Attademo, 2017). The Italian case study is the Metropolitan Area of Naples. It includes 92 municipalities on a total area of $1.171 \mathrm{~km}$, inhabited by 3.117 million people. In this area, between 1994 and 2009, the Regional Waste Emergency, and the newest phenomenon of the so-called "Land of Fires" increased the environmental risk from soil pollution (Berruti \& Palestino, 2019). These crises depend on both the government inabilities and on the poor governance of waste management (REPAiR, 2017). Acting as a driver for further improper land uses and for out-of-control activities, the waste emergencies contributed to turning open spaces and agricultural plots into abandoned and neglected landscapes (Berruti \& Palestino, 2017). In this context, circularity represents a key challenge for designing a waste supply-chain capable of improving job creation and fostering social acceptance locally.

Whithin the Metropolitan Area of Naples, the research defined a Sample Area (Figure 2). Such identification has

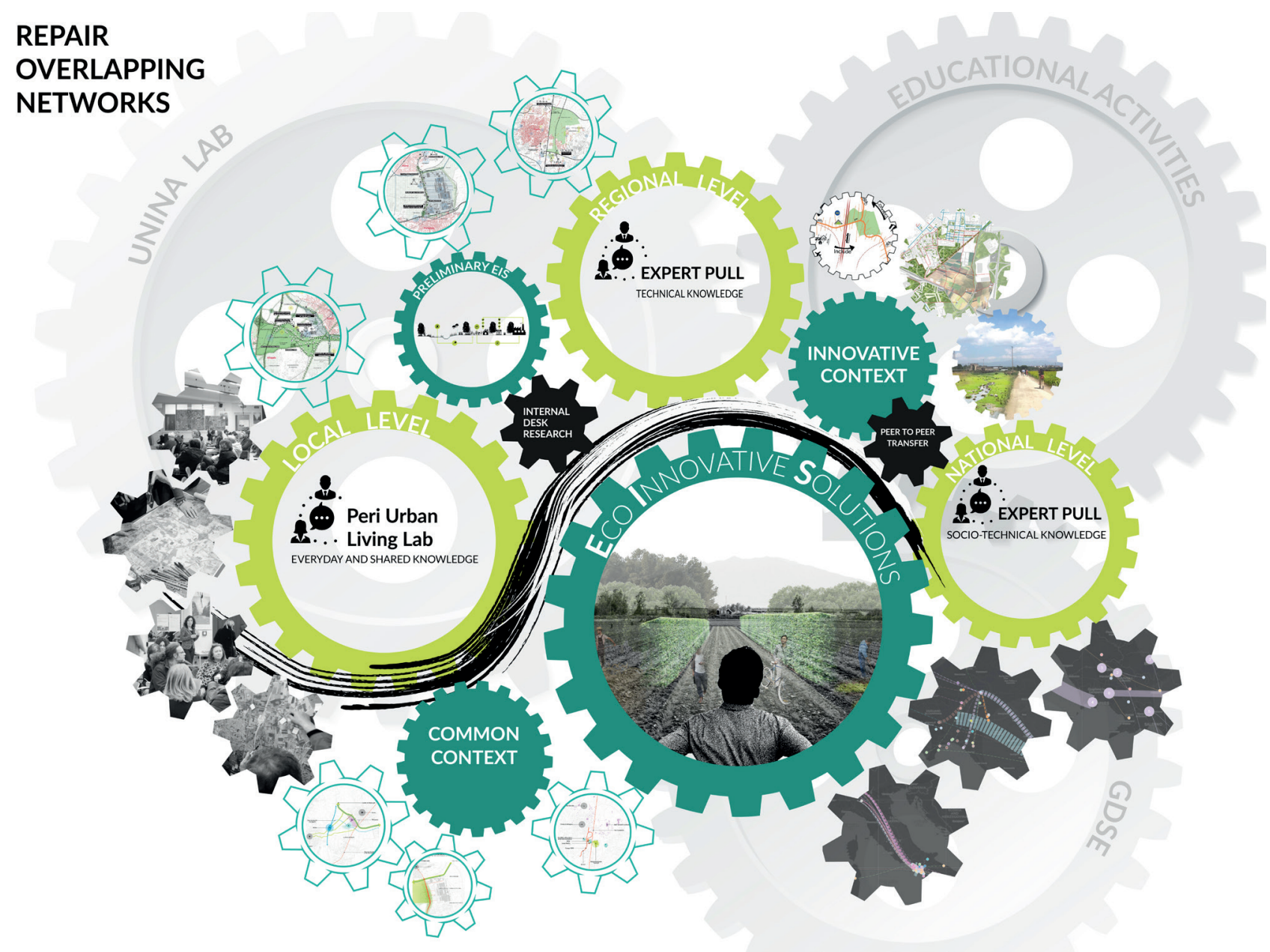

FIGURE 1: Overlapping networks (UNINA graphics). 


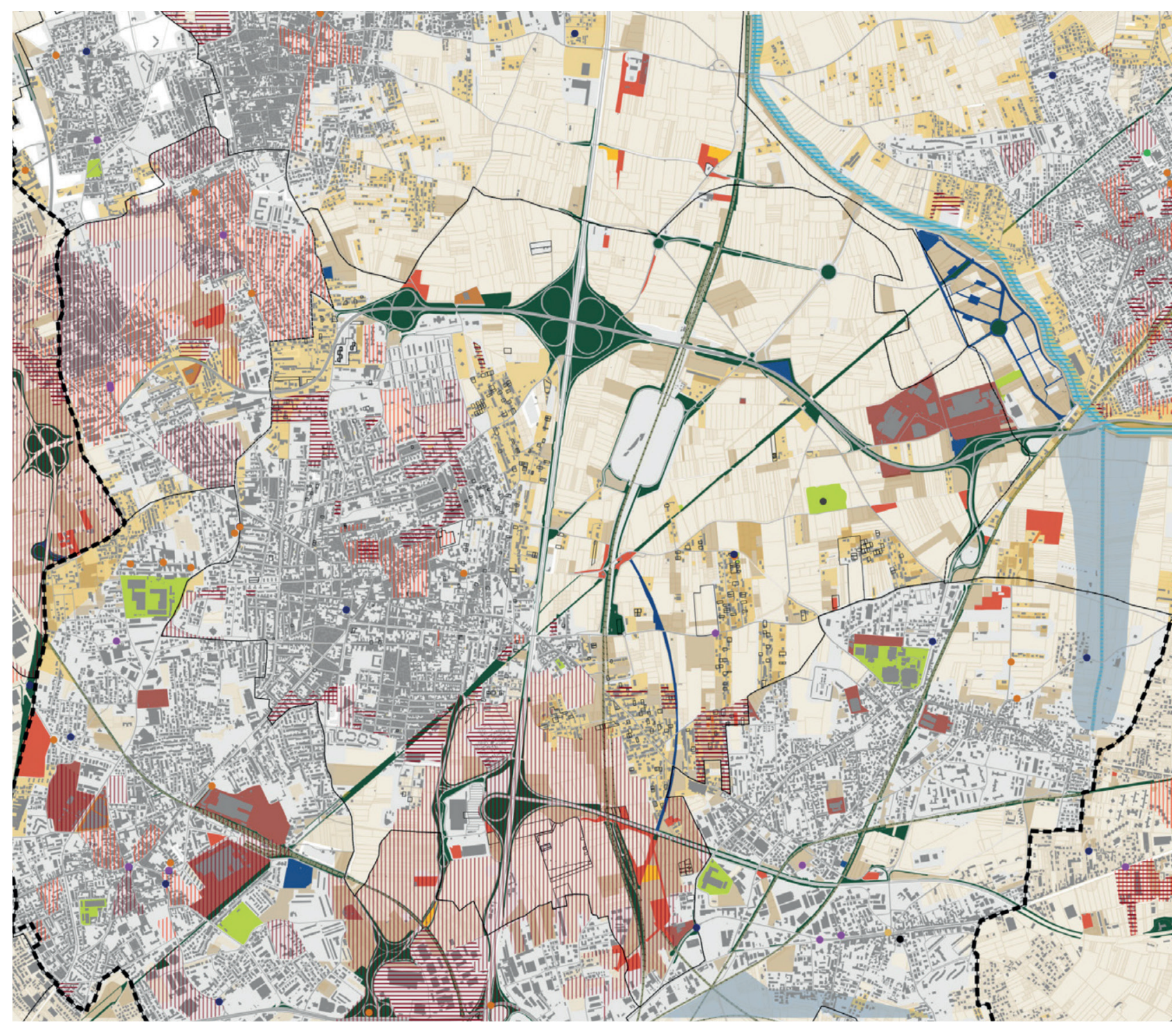

\section{CODE LEGEND}

nsw1.1. Polluted soils

nsw1.2. Artificial soils

nsw2.1. Degraded water bodies

nsw2.2. Elements linked to degraded water bodies

nsw2.3. Flooding zones

nsw3.1. Abandoned agricultural fields

nsw4.1. Vacant/underused buildings and settlements

nsw4.2.

nsw4.3 |||||||||| Poor housing condition

nsw4.4. Informal settlements

nsw4.5. Urban lots in transformation/tampered

nsw4.6. Unauthorized buildings and settlements

nsw 4.7. $\square$ Confiscated assets

nsw5.1. Neglected - dismissed or underused infrastructures

nsw5.2. Dismissed or underused public facilities

\section{CODE LEGEND}

nsw5.3. Interstitial spaces of infrastructure facilities

nsw6.1. - Waste incinerators

nsw6.2. - Landfills

nsw6.3. - Storage facilities

nsw6.4. - Waste recovery

nsw6.5. - Sorting

nsw6.6. - Communication

nsw6.7. - Mobile facilities

nsw6.8. - Purification

nsw6.9. - Composting

nsw6.10. • Incinerators

nsw6.11. • Vehicle dismantling

nsw6.12. - Other

FIGURE 2: Case study area (UNINA graphics). 
been made based on the activities of the PULLs, and it aims at defining a smaller area featured by the same physical, socio-ecological and administrative characteristics that describe the entire Metropolitan Area of Naples.

\subsection{Definitions adopted}

\subsubsection{Eco-innovation}

The starting point of the study has been the EU definition of eco-innovation as both technological and non-technological innovation «that create business opportunities and benefit the environment by preventing or reducing their impact, or by optimising the use of resources [...] It encourages a shift among manufacturing firms from "end-of-pipe" solutions to "closed-loop" approaches [...] by changing products and production methods - bringing a competitive advantage across many businesses and sectors» (EC, 2014). Such definition stresses the need for achieving a comprehensive approach to innovation, putting in evidence the request of win-win solutions able at improving environmental efficiency as well as social and economic investments. In order to do this, the research defines Eco-Innovative Solution as «elementary responses to case-specific problems, in a contextual approach towards innovation, where the real innovation is the process to achieve the result» (REPAiR, 2018).

\subsubsection{Circular Economy}

The study refers to the definition of a circular economy as «an industrial system that is restorative or regenerative by intention and design. It replaces the 'end-of-life' concept with restoration, [...] and aims for the elimination of waste through the superior design of materials, products, systems, and, within this, business models» (Ellen MacArthur Foundation, 2013, p.7). Such definition looks at a quantitative reduction of waste flows according to territorial and socio-economical interfaces. Hence, it refers to the business model as a not-neutral tool for oriented regenerative and/or restorative processes, thus shifting the concept of circularity from the single field of the environmental care to that of industrial and social innovation.

In the framework of the REPAIR research, the principles of circular economy are mainly referred to design waste supply chain featured by being adapted to the local productive context and to the social practices. Further, this research posits short waste supply chain as a key goal, both in order to identify technical and social constraints locally, and overcome the typical CE model, focused on resource-reduction approach (Ellen MacArthur Foundation, 2015). The research works on the circular reuse of wasted materials (CDW and OW) through a systemic planning approach, designing the waste supply chain as a technical and economic opportunity for the regeneration of peri-urban landscapes, especially those abandoned or polluted (Formato, Attademo, \& Amenta, 2017).

\subsection{Designing innovative strategies}

\subsubsection{Waste flows analysis}

The research approach starts from the analysis of waste flows (C\&D waste and organic waste) within the case study area by the aim of detailing their life cycle assessment (LCA), and of spatializing their flows at local and national scale. Data collecting was made thanks to the data source of Regione Campania, and according to the constraints of the Geodesign Decision Support Environment (GDSE) model, that is part of the REPAIR innovative approach to planning. GDSE is a web-based open-source tool that adapts the geodesign framework for the purpose of spatial diagnosis and elaborates scenarios about the application of systemic eco-innovative strategies to territories (Arciniegas et al., 2019). Thanks to the GDSE tool, we visualize the different typologies of C\&D waste flows and the organic flows within Italy, specializing the relationship between the waste production sites and their destination inside and outside Campania Region (Figure 3).

Waste flows analysis shows most of both C\&D and organic waste flows directed out of the Region. Such resultants are consistent with the fact that few treatment plants work in the study area, but above all, it reflects the social difficulty to accept the construction of new ones. With regard to the technical constraints, the main barrier in recycling organic waste is the lack of efficiency in the household refuse selection - mainly dependent on the final user's skills. The lack of user's ability in waste selection produces low quality material, not consistent with the requirements for returning recycled organic substances (namely compost) in the biological cicle. Similarly, the deficiency of guidelines and protocols for facilitating building demolition, places construction debris into the "special waste" list, due to the pollutants potentially embedded in (Codice dell'Ambiente, d.lgs n.152/ 2006); further, the cost of a waste audit, together with the difficulties to re-introduce debris into the construction supply-chain as secondary raw material, reduce the opportunities for recycling and reusing C\&D waste. In addition, the special condition of the case study area, affected by both poor social context and informal/ illegal activities, makes the control of the debris disposal very hard, so that the unauthorized dumping is recognized as a public emergency in the area.

2.3.2 Innovative design process: collaborative networks for devising waste supply chain

With the aim of integrating waste reduction goals into peri-urban planning, the research provides a collaborative design process for making waste supply-chain part of the future territorial development. The research develops a proper method for involving stakeholders into the project, designing collaborative networks for enhancing co-design within a panel of experts and beneficiaries, both acting in the context of the case study area. In order to do this, a number of Peri-Urban Living Labs (named PULLs) (REPAiR 2018) were planned since the beginning of the project in 2016. They are aimed at facilitating knowledge transfer through different subjects and different goals, according to the Lab participants specific. The results of the different Labs were discussed within all the subjects involved, adopting the process of the "overlapping networks". The latter was designed as dedicated Labs, where both expert and not-expert subjects can merge their different competences. The purpose of these networks is to collaborate 


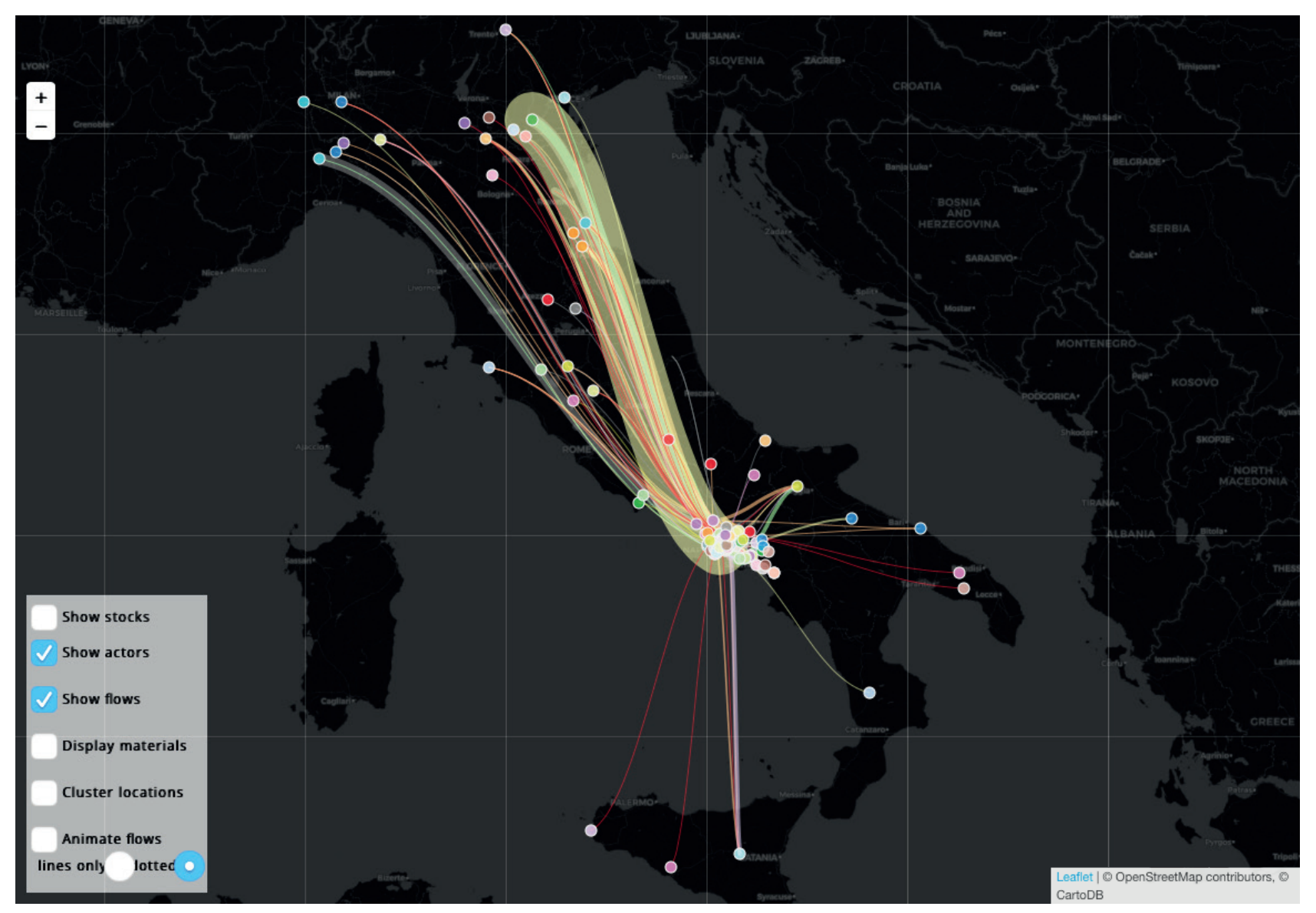

FIGURE 3: Existing organic waste flows in the case study area (UNINA graphics).

in devising proposals for shortening the C\&D waste and organic waste supply chains, enhancing the many points of view, and the specific knowledge about the site-specific potentials and constraints. Such method merges together the goals of co-designing and validating new products (techno-soils). A further focus was given to the proposal of using techno-soils for planning new green infrastructure and public spaces in the peri-urban area. Techno-soils have been here interpreted as innovative resources to be reused thanks to the implementation of more sustainable, inclusive and circular waste metabolisms, decoupling economic growth from resource consumption and environmental depletion (UNEP, 2011).

The strategy adopted aims at streamlining the main criticalities affected the waste flows management and discussing effective solutions for reducing waste ${ }^{1}$. The research identifies the following steps:

a. Recognizing wastescapes in the case study area;

b. Providing potentials scenarios for improving OKM supply-chain for C\&D waste and Organic Waste;

c. Producing a comprehensive master plan for both improving peri-urban environment and waste management.

Participants co-created several GIS-based maps of the case study area, in which the layers of spatial information were overlapped to those related of the wastescape per- ceptions, and discussed (Figure 4). Such methodology implements the comprehensive understanding of peri-urban area, and improves the site description with both the overlay of thematic maps (based on the official data-sources) and further layers, coming from bottom-up information. Description is here considered as the main conceptual tool for catching the inner characteristics of the place. Therefore, information coming from the Repair Labs supports the mapping process in recognizing abandoned and neglected areas in the Sample Area, and producing a new understanding about planning opportunities (Figure 5).

According to the advances produced, the co-design process provided three eco-innovative solutions aimed at creating a tentative frame of action for implementing waste management (Rigillo et al., 2018). Starting by the waste flows analysis (C\&D Waste and Organic waste) the research groups developed the spatial proposal for waste supply-chain into the sample areas, promoting different potential scenarios (Russo et al., 2019). Each proposal takes advantages from the skilled views of the Peri-Urban Living Labs (PULL) participants, and from the opportunity of depicting criticalities at a local scale.

Therefore, the research introduces a Master Plan for waste reduction (Figure 5), running on the following points:

1. Free C\&D waste disposal sites, aimed at intercepting those construction and demolition waste that could not otherwise be transferred to the recycling sites (i.e. de- 


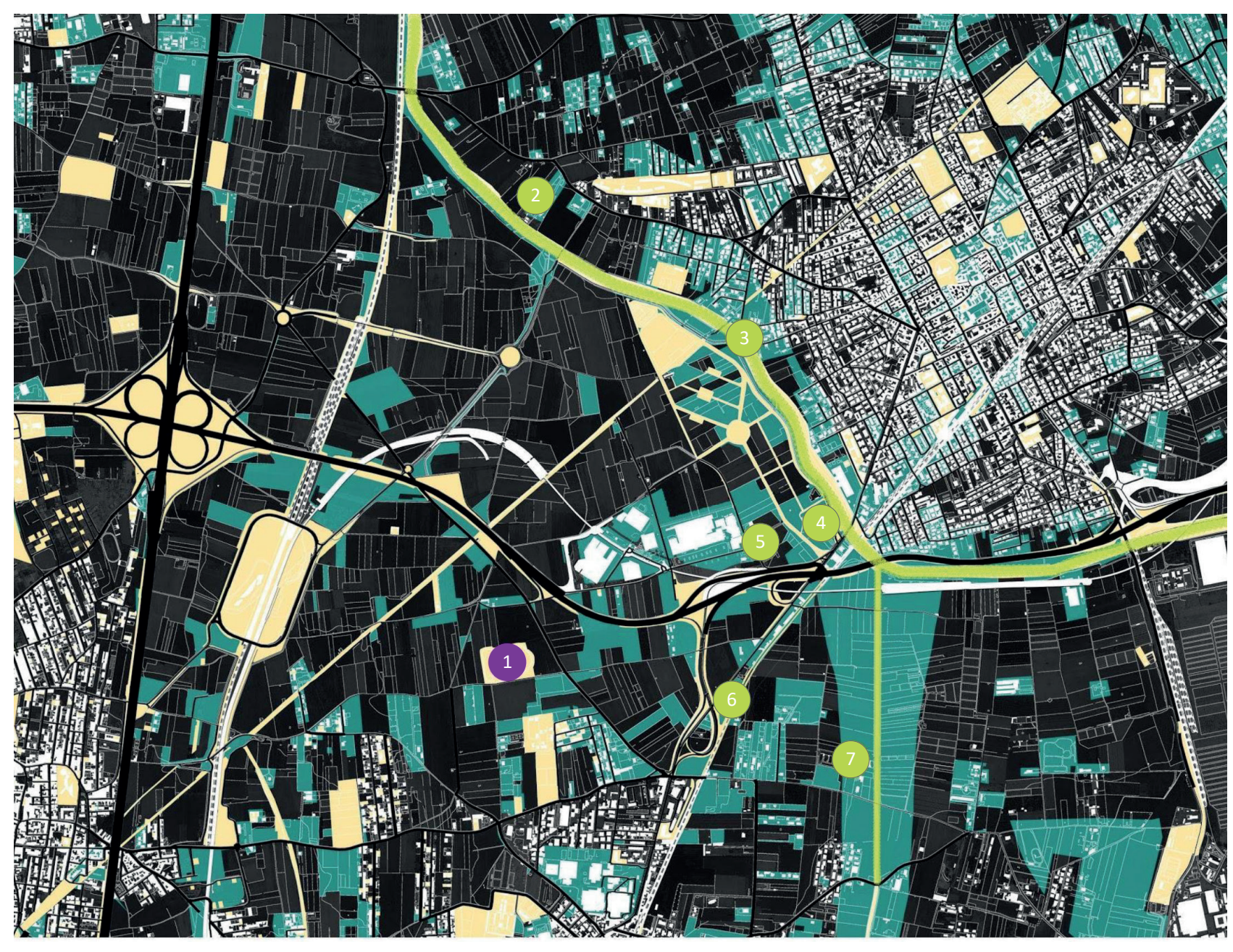

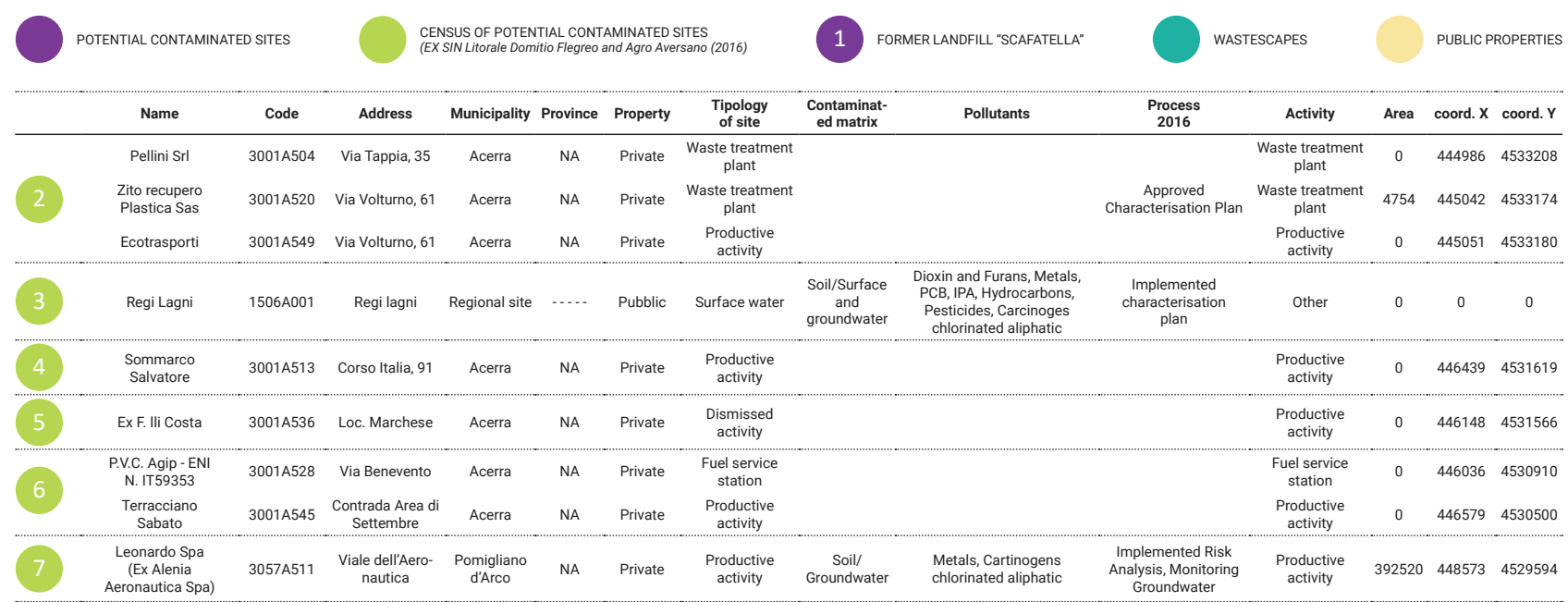

FIGURE 4: Existing organic waste flows in the case study area (UNINA graphics).

bris from small household works, done without administrative requirements or executed by poor construction companies);

2. C\&D waste recycling sites (disassembling, reuse and zero-km selling), aimed at extending the life cycle of construction products and materials;

3. Inclusion of organic waste disposal sites into public and private spaces (and roads), aimed at promoting friendly-users waste collection sites in streets and household condominiums;

4. Design of treatment plants for recycling of organic waste. The aim is to avoid the concentration of big treating plants into hyper-specialized spaces, for facilitating social acceptance, merging new sustainable public spaces with operational infrastructures of waste; 


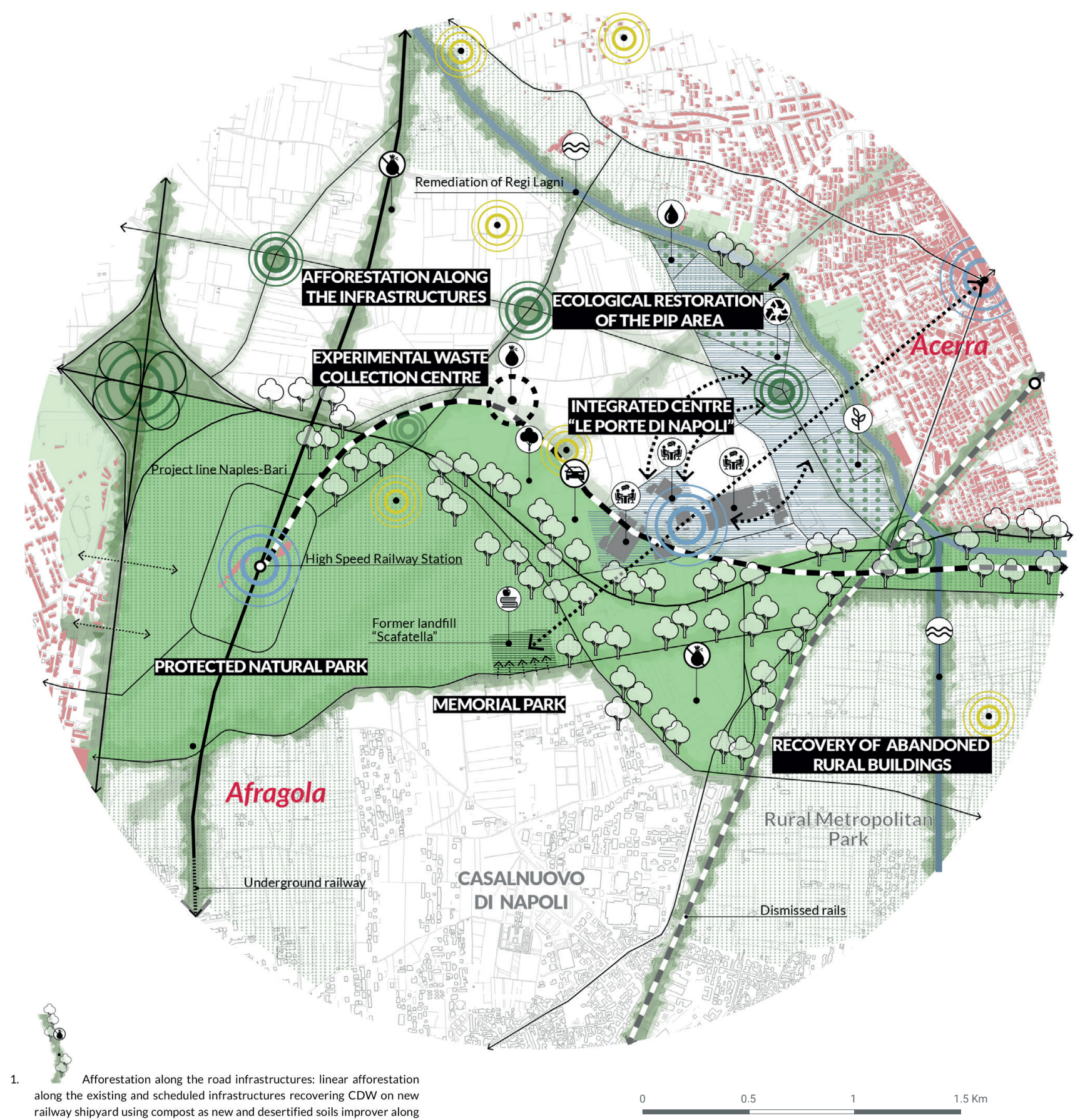
the infrastructures.

\section{(2)}

2. - Protected natural reserve: creation of a protected natural park vehicular traffic restrictions; delimiting of a natural "border" to define the perimeter of the park.

$$
\because
$$

3. $\because . .$. Experimental recycling point: creation of an experimental waste collection centre in the abandoned parking along the Asse Mediano infrastructure; selection and first treatment of waste by a "KmO" recycling plant located on an adjacent wastescape; installation of electricity production technologies from kinetic energy generated by vehicles.

(a)

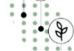

4. Ecological re-functioning of the productive area (PIP area): reuse of the Acerra PIP area with environmental and ecological purposes; wetlands to reclaim the water of Regi Lagni and allocation of compatible productive functions connected with the shopping centre.

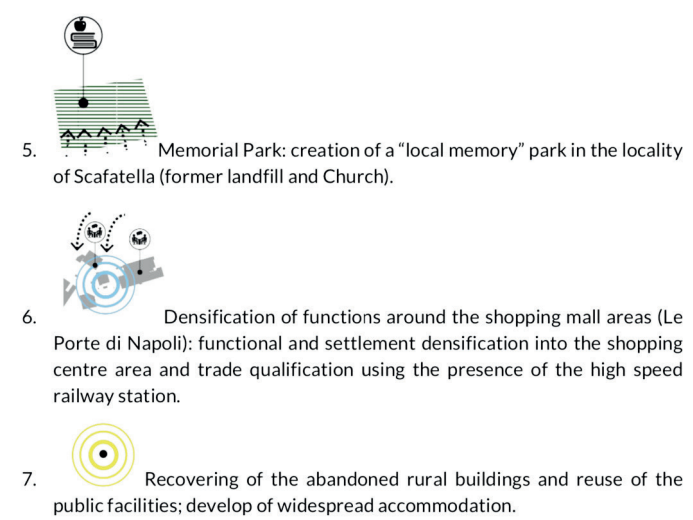

FIGURE 5: Proposed masterplan: New lands strategy (Graphics UNINA TEAM 2018). 
5. Locating new eco-districts and green infrastructures within the Master Plan, aimed at placing soil production into the waste supply-chain, so that new artificial soils could represent an effective, response within landscape re-development operations.

\subsubsection{Innovative products: designing artificial soils}

The design of artificial soils, thanks to the reuse of construction debris, is aimed at implementing the products typologies coming from C\&D waste recycle. New technological soils are part of the proposal of green peri-urban infrastructure targeted at providing ecosystem services and at raising the level of the existing living conditions. The proposal refers to the typically War World II bombing debris management, where C\&D waste was used as hard soils, while excavated soils as well as composting of organic waste treatment will be combined for realized top soils (Figure 6). These new soils will be seeded by pioneer plants such as the Arundo Donax and other local species. Arundo Donax, especially, has been selected because its soil remediation capacity (Kennenk \& Kirkwood 2015; Bonfante et al. 2017).

The research focused on techno-soils for implementing "green-infrastructure" and "new soils" as models for testing a sort of "new recycled product". The study especially deepens the opportunities of new green border-belts, as a sort of "green-grey infrastructure" along the existing motorways, which can also host areas of C\&D waste collection, and first treatment areas of post-construction waste (Figure 7).

\section{DISCUSSION}

Co-design is more than simply sharing of and transacting on resources, risk and reward. It refers to specific culture both about technical tools and social innovation (Manzini, 2015). It is about integrating across different value nodes throughout the ecosystem and thereby creating new markets and more effective business models, which wouldn't exist otherwise (EU 2016). Hence, the renewing of the existing behaviours and patterns (technological, socio-political, environmental and economic) represent a key target for implementing circularity. Especially, circularity has to merge collaborative processes to produce increasing consciousness, and many types of responses according to different contexts and categories:

- Products-related innovation, as the so-called eco-innovative solutions (including techno-solis), to implement circularity;

- Process-oriented innovation, as the development of new decision-making models, collaboratively building interactions and connections within un-expected actors;

- Services-proactive innovation, as the ultimate goal is the mixing between competences and opportunities, in order to increase circularity feasibility.

Circularity is an urgency for urban planners and decision makers. The design experience produced by Naples research group starts from local scale analysis, looking at the site-specific problems/ objectives/ priorities for pro-

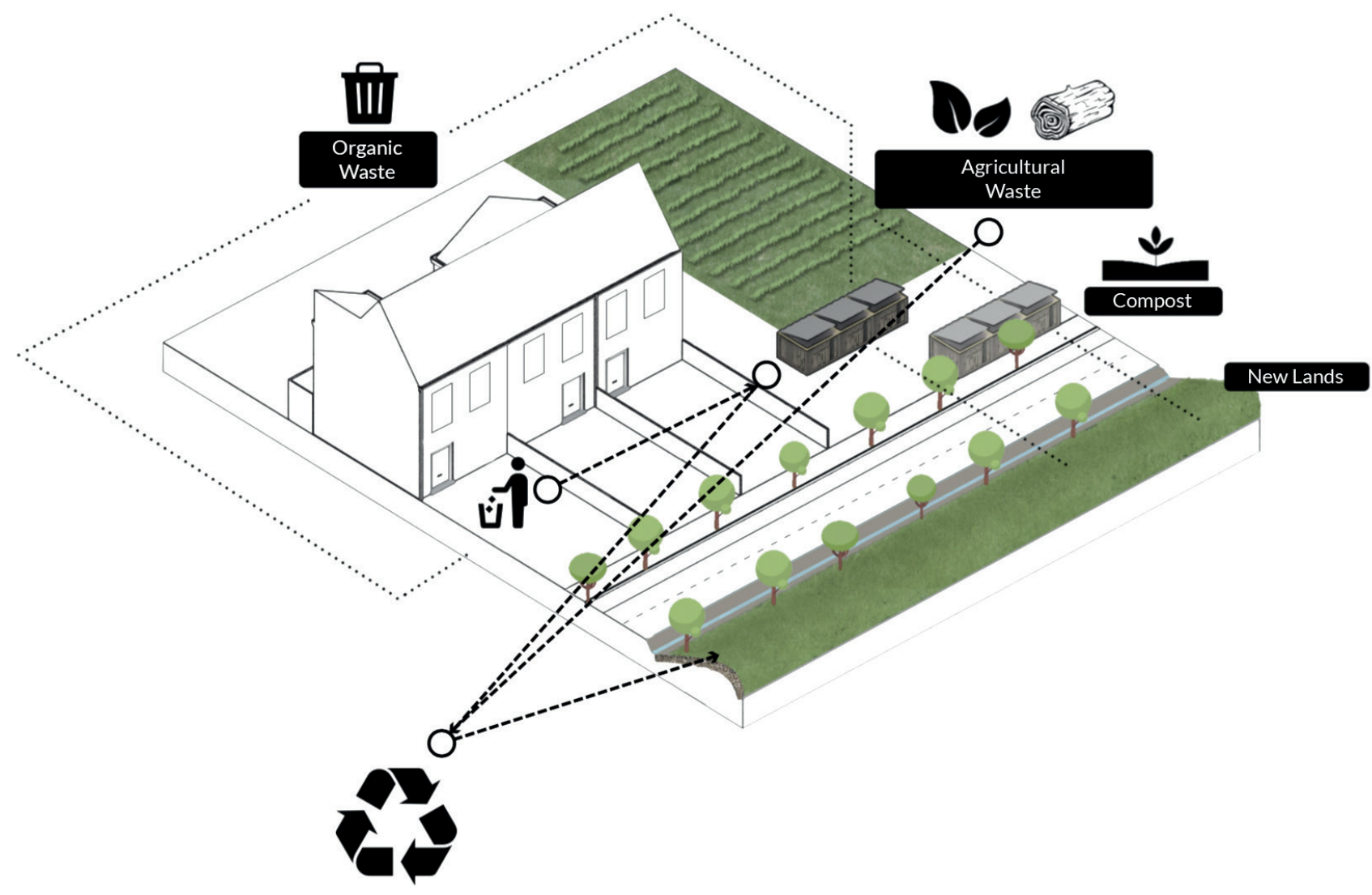

FIGURE 6: C\&D Waste recycle process (Graphics UNINA TEAM 2018). 


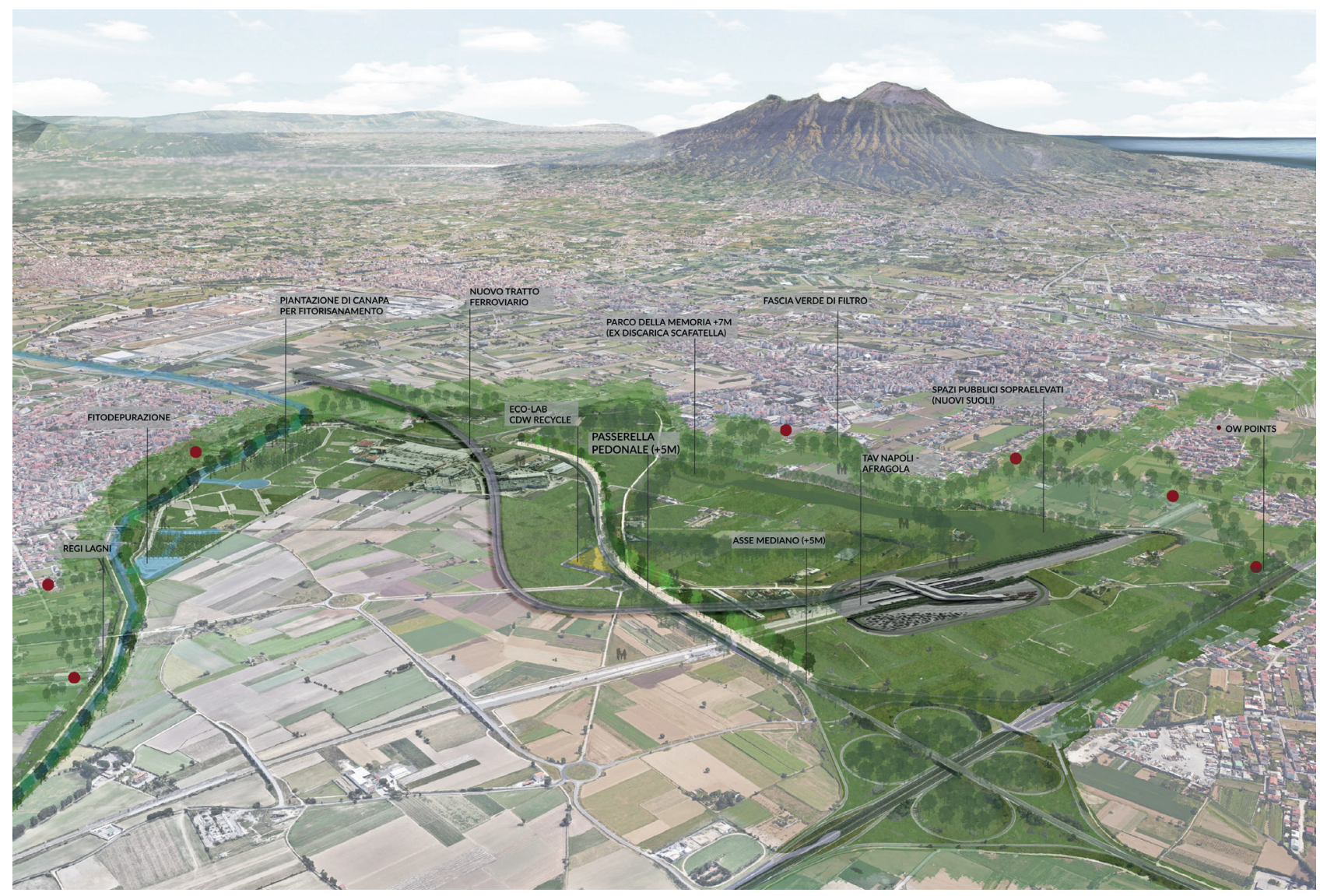

FIGURE 7: Peri-urban green infrastructure (Graphics UNINA TEAM 2018).

ducing simple and transferable solutions. In this case, the mapping activity is crucial for reaching a common awareness of peri-urban problems, and for recognizing opportunities and criticalities at local scales. Further, circular and multi-scale processes generate effective proposals for short supply-chain based on the local capacities of actors and stakeholders, enhancing embedded skills and visions. In addition, the analysis of waste flows together with the map of existing wastescapes provided an operational framework to apply innovative strategies and technologies to facilitate a sustainable transition towards better territorial conditions of welfare, liveability, and cooperation around stakeholders.

In order to do this, PULLs achieved a common understanding that there is no real empowerment of stakeholders without the availability to put themselves at stake and to take action in the process. Within this research, stakeholders' participation has been considerd the precondition for co-creation of solutions capable of activating circularity and change models.

Further, the Living Labs (LLs) philosophy is in line with the shift from a product-oriented economy towards a service-oriented economy. LLs rely on Public-Private-People-Partnerships (PPPP), as citizens and local associations are considered as an important source of knowledge and experience for the innovation process (Innovation Alcotra, 2013). This collaborative approach among actors defines specific "enabling conditions", supporting the identification of operative tools and facilitating decision-making processes.

The combine C\&D waste and organic waste into new artificial soils represented a low-cost opportunity to activate an incremental decision-making process capable of designing operational models for circular economy applied to both the selected waste typologies and peri-urban landscapes. The loop of decision-making process becomes an action of legitimacy for its achievements, as well as positive feedback which builds trust among the participants, while wicked problems can be driven out through new collaborative and cooperative processes.

\section{AKNOWLED GEMENTS}

This study was developed with the financial support of HORIZON 2020 - RE-PAiR: REsource Management in Peri-urban ARreas: Going Beyond Urban Metabolism - Grant agreement No 688920 lead by Delft University of Technology (NL), and supervised for the Italian part by professor Michelangelo Russo. Authors thanks the whole research staff for supporting the production of the paper.

\section{AUTHORSHIP}

Marina Rigillo and Enrico Formato conceived the presented idea. Enrico Formato developed the theory on wastescape mapping and performed the GIS-Based maps. Marina Rigillo developed the theory on recycling C\&D waste 
as techno-soils and the short supply-chain as co-design outcomes. Michelangelo Russo supervised the findings of this work. All authors discussed the results and contributed to the final manuscript.

\section{REFERENCES}

Berruti, G., \& Palestino, M. F. (2017). La pianificazione del ciclo dei rifiuti e delle aree rifiuto nella svolta della governance metropolitana di Napoli. Working Papers Rivista Online Di Urban@it, 3, 2-11

Berruti, G., \& Palestino, M. F. (2019). Contested land and blurred rights in the Land of Fires (Italy). International Planning Studies, 1-12. https://doi.org/10.1080/13563475.2019.1584551

Bonfante A., Impagliazzo A., Fiorentino N., Langella G., Mori M., Fagnano M. (2017) Supporting local farming commuities and crop production resilience to climate change through giant reed (Arundo donax L.) cultivation: an Italian case study, Science of the Total Environment, Volumes 601-602, December 2017, pages 603-613

$\operatorname{COM(2015)~} 614$ final, L'anello mancante - Piano d'azione dell'Unione europea per l'economia circolare, Comunicazione della Commissione al Parlamento Europeo, al Consiglio, al Comitato Economico e Sociale Europeo e al Comitato Delle Regioni

EC. (2010). Being wise with waste: the EU's approach to waste management

EC. (2014). Towards a circular economy: A zero waste programme for Europe. European Commission

EC. (2018). EU Construction and Demolition Waste Protocol and Guidelines, published on 18.09.2018, available at https://ec.europa.eu/ growth/content/eu-construction-and-demolition-waste-protocol-0_en accessed 9.12.2019

EC Horizon 2020. (2019). Waste: a resource to recycle, reuse and recover raw materials. Retrieved February 11, 2019, from https:// ec.europa.eu/programmes/horizon2020/en/h2020-section/waste

EEA European Environment Agency. (2015). Waste prevention: where do European countries stand? European Environment Agency

EU Commission (2016) "Open Innovation, Open Science, Open to the World. A vion for Europe", Directorate-General for Research and Innovation

Ellen MacArthur Foundation (2013), "Towards the Circular Economy, Opportunities for the Consumer Goods Sector" (https://tinyurl. com/ztnrg24)

Ellen MacArthur Foundation (2015), "Towards a Circular Economy: Business Rationale for an Accelerated Transition" (https://tinyurl. com/zt8fhxw)
Fagnano et al., (2018). The Ecoremed protocol for an integrated agronomic approach to characterization and remediation of contaminated soils. Italian Journal of Agronomy 13(s1), pp. 34-44. ISSN $1125-4718$

Formato, E., Attademo, A., \& Amenta, L. (2017). REPAiR "Wastescape" e flussi di rifiuti: materiali innovativi del progetto urbanistico. Special Issue Urbanistica Informazioni X Giornata Studio INU "Crisi e Rinascita Delle Città" $10^{\circ}$ INU Study Day "Crisis and Rebirth of Cities" a Cura Di/Edited by Francesco Domenico Moccia e Marcihela Sepe, Marzo-Apri(272 s.i.). ISSN 0392-5005

Innovation Alcotra. (2013). La creazione di Living Lab transfrontalieri. Torino

Kennenk K., Kirkwood N. (2015) Phyto. Principles and resources for site remediation and landscape design, Routledge, London and New York

Manzini E. (2015), Design when everybody designs. Introduction to Design for Social Innovation, MIT Press

REPAiR. (2017). Governance and Decision-Making Processes in Pilot Cases Deliverable 6.1. EU Commission Participant portal. Brussels. Grant Agreement No 688920. EU Commission Participant portal. https://doi.org/10.4233/uuid:30c806a9-9b80-45a9-89a0db1ea7c0

REPAiR. (2018). Handbook: how to run a PULL Deliverable 5.4. EU Commission Participant portal. Brussels. Grant Agreement No 688920.

REPAiR. (2018). Eco-Innovative Solutions Naples Deliverable 5.3. EU Commission Participant portal. Brussels. Grant Agreement No 688920

Rigillo, M., Amenta, L., Attademo, A., Boccia, L., Formato, E., \& Russo, M. (2018). Eco-Innovative Solutions for Wasted Landscapes. Ri-Vista, 16(1), 146-159. https://dx.doi.org/10.13128/RV-22995

Russo M., Amenta L., Attademo A., Cerreta M., Formato E., Garzilli F., Mazzarella C., Rigillo M., Vittiglio V. (2019), Short Supply Chain of Waste Flows for Landscape Regeneration in Peri-Urban Areas, in Proceedings Sardinia 2019 / Seventeenth International Waste Management and Landfill Symposium/ 30 Sept - 4 October 2019 S. Margherita di Pula, Cagliari, Italy / (c) 2019 by CISA Publisher, Italy, pp. 1-1

Steen, K., \& Bueren, E. van. (2017). Urban Living Labs. A living lab way of working. Amsterdam Institute for Advanced Metropolitan Solutions Delft University of Technology. Retrieved from https://www. ams-amsterdam.com/wordpress/wp-content/uploads/AMS-Living-Lab-Way-of-Working_small.pdf

UNEP, 2011, Towards a Green Economy: Pathways to Sustainable Development and Poverty Eradication - A Synthesis for Policy Makers, www.unep.org/greeneconomy

${ }^{1}$ The main problems/challenges identified in the overall process are:

- Campania waste emergency;

- Criminal economy competing with the public waste management;

- Transition from Province to Metropolitan City with the consequent ongoing change;

- Institutional difficulties of overcoming sectors in order to co-design policies;

- Lack of shared knowledge between the sectors and towards citizens;

- Mistrust of citizens towards public institutions;

- Suspicion on the proposals of reusing waste;

- Proliferation of wastelands and wastescapes (D5.3 Eco-Innovative Solutions Naples). 